\title{
Buffered forgetting: When targets and distractors are both forgotten
}

\author{
Clinton S. Weeks and Michael S. Humphreys \\ University of Queensland, Brisbane, Australia \\ AND \\ William E. HockLey \\ Wilfrid Laurier University, Waterloo, Ontario, Canada
}

\begin{abstract}
In three experiments, we investigated prior findings that, following some memory tasks, essentially flat $d^{\prime}$ or forced-choice retention curves are produced. These curves have been interpreted as indicating that forgetting is not present over the intervals examined; however, we propose in this article that forgetting is actually present whenever hit rates and false alarm rates are both declining, despite the result being a flat retention curve. We demonstrate that such curves can be produced using a pair recognition procedure, a plurality discrimination task, and a verbal discrimination task. For all of these tasks, we provide either new evidence or refer to evidence already in the literature that tends to contradict alternative explanations. Then we show how the failure to consider both signal strength and noise has led to distortions in theoretical thinking about forgetting.
\end{abstract}

Differences have been found between the forgetting functions for single items and pairs using the quasicontinuous recognition paradigm, such that, over short retention intervals, memory for single items appears to decline quite rapidly, whereas memory for pairs appears to be quite stable (Hockley, 1991, 1992). This has been widely interpreted as showing that associative information is not forgotten over these intervals (Hockley, 1991, 1992; Murdock \& Hockley, 1989). Similarly, memory for source has been reported as being relatively stable over short retention intervals, the interpretation of this being that recollection is stable over short retention intervals (Yonelinas \& Levy, 2002). Although it is clear that Hockley's pair recognition forgetting curves were relatively flat, and similarly that Yonelinas and Levy's recollection curve was for the most part flat, we must be cautious about interpreting these as being indicative of an absence of forgetting, given that these flat curves were the result of parallel declines in hit rates (HRs) and false alarm rates (FARs). Instead, we propose that such forgetting should be referred to as being buffered, where forgetting appears to be slower than it actually is. ${ }^{1}$ More generally, we propose that, in order to understand forgetting, one has to identify both signal and noise components and determine how each changes over the retention interval.

To examine the retention function of associative information via pair recognition, Murdock and Hockley (1989) used a quasicontinuous recognition procedure. Study items were pairs of unrelated words, interspersed with intact and rearranged pair test probes at lags of up to 16 intervening presentations. They assessed recognition accuracy using $d^{\prime}$ estimates and found that pair recognition was relatively stable across the short retention intervals examined. Specifically, as test lag increased, participants made fewer hits (yes responses to intact pairs), but also fewer false alarms (yes responses to rearranged pairs), thus producing a stable $d^{\prime}$ retention curve. Hockley $(1991,1992)$ extended the procedure in order to compare single-item and pair retention rates within a single list. Experimental lists consisted of unrelated-word-pair study trials, single-item test probes based on items from pair study trials, and pair test probes also based on the pair study trials. Across this series of experiments, test lag ranged from 2 to 24 intervening presentations, and recognition accuracy was again assessed using $d^{\prime}$. Results suggested that single-word item recognition rates declined more rapidly than did word pair recognition rates, using lists composed of both nouns and nonnouns (1991, Experiment 1) and lists containing high and low frequency word pairs (1991, Experiment 2), and that these trends were independent of participants' overall levels of accuracy (1991, Experiment 2) or the amount of confidence they placed in their recognition judgments (1991, Experiment 3). Hockley (1992) also demonstrated that the same differential forgetting rates occurred using both old-new response techniques (1992, Experiment 1) and forced-choice response techniques (1992, Experiments 2, 3A, and 3B).

Yonelinas and Levy (2002) also reported unusual forgetting curves in a quasicontinuous source monitoring paradigm - which they suggested indicated differential

M. S.Humphreys, mh@humanfactors.uq.edu.au 
forgetting (i.e., that familiarity declines and recollection is stable) - and proposed a dual process explanation intended to apply to both source monitoring and pair recognition. These researchers presented study words in a red or green font color and interspersed these with tests in a neutral font color. They were interested in the extent of participants' recollection of associative information about the test item (font color) in comparison with the extent of their familiarity with test items (words). On half of the test trials, participants were asked whether the test item had been studied in a red font, and on the other half, they were asked whether it had been studied in a green font. Thus, the test question could be either congruent with the study event (e.g., studied in red, with the question being asked in red) or incongruent with the study event (e.g., studied in red, with the question being asked in green). New items were also tested. Participants were supposed to respond "yes" if they believed the test question to be congruent with the study event and "no" if they believed it to be incongruent or new. They were also instructed to respond "yes" to items for which color could not be recollected (but where the item was familiar) and "no" if color could not be recollected and the item was not familiar. Yonelinas and Levy's rationale for this response method was that incongruent questions should only receive a yes response when the test items were familiar (since recollection would lead to a no response); thus, the probability of a yes response to an incongruent question across lag would provide an index of familiarity. If the probability of yes responses to incongruent questions were to decline across lag, it could be concluded that familiarity would also decline. The same decline could be expected for congruent questions if recollection does not decline. If, however, both familiarity and recollection were to decline, the two curves should not decline in parallel, but should converge. In their results, Yonelinas and Levy found that the probability of responding "yes" to congruent questions declined with lag, and the probability of responding "yes" to incongruent questions initially rose, but then declined in parallel with yes responses to congruent questions. Their conclusion was that, from a lag of about 8 onward, recollection was stable (see Figure 1). ${ }^{2}$

Yonelinas and Levy (2002) attributed the flat retention function (parallel curves) at the longer lags to the stability of recollection, and they attributed the decline in the probability of a yes response for both congruent and incongruent questions to a decline in familiarity. They also proposed that the same explanation could apply to Hockley's $(1991,1992)$ pair recognition findings. In the theory advanced by Yonelinas and Levy, there is a high level of familiarity at short lags for both items within a pair, and this results in a high HR and FAR in pair recognition at the earliest lags - that is, responding based on item familiarity results in both intact and rearranged pairs being judged as old - and in the probability of saying "yes" to both congruent and incongruent source monitoring questions. Because familiarity is assumed to rapidly decline as lag increases, there is a roughly parallel decline in HR and FAR in pair recognition and in yes responses to congruent and incongruent questions in source monitoring.
This conclusion about the stability of recollection and the rapid loss of familiarity is surprising given previous results that showed the opposite pattern. Yonelinas (1994) used the process dissociation procedure to examine the effects of list length on estimates of familiarity. In his second experiment, participants studied two 6-item lists or two 18 -item lists. Items were presented at a 2 -sec rate with a 5-sec interval between lists, so the retention interval was considerably longer for the long list condition than for the short list condition. The shortest retention intervals in the Yonelinas (1994) study are roughly comparable to the lags of 16 and 32 used in the present study. Yonelinas (1994) found that estimates of recollection declined over these intervals and that there was no change in estimates of familiarity. Rubin, Hinton, and Wenzel (1999) have also shown that, in a quasicontinuous paradigm, cued recall declines steeply over the same intervals used by Yonelinas and Levy (2002). This suggests that the stable recollection observed by Yonelinas and Levy is not cued recall, which has been assumed to be the recollection component in pair recognition since Mandler (1980).

In addition to the doubts raised by these divergent findings, the Yonelinas and Levy (2002) argument needs to be evaluated with respect to two critical assumptions not directly addressed in that paper. The first is that the information used to discriminate between two sources (recollection) is all-or-none. This assumption has been challenged by three alternate theories proposed in three distinct studies (Banks, 2000; Dennis \& Humphreys, 2001; Heathcote, Raymond, \& Dunn, 2006). The second assumption is that false recollection does not occur. That is, participants do not falsely recollect for new items and do not recollect information that indicates participants' associating the wrong source with old items, including falsely interpreting the information they do recollect. At one point in the literature, it appeared that the presence of linear receiver operating characteristic (ROC) curves supported the all-or-none assumption (Rotello, Macmillan, \& Van Tassel, 2000; Yonelinas, 1999). However, it now appears that curvilinear ROC curves are the norm (Heathcote et al., 2006), and that recollection is not, therefore, all-or-none. More importantly, Heathcote et al. introduced a procedure that showed the standard dual process account not to be viable. That is, they looked at list discrimination and plurality discrimination with and without new words in the test list. They argued that the elimination of new items should reduce participants' use of familiarity, producing more evidence for recollection-ROC curves that were more nearly linear. Their reasoning was that, with list discrimination, familiarity was useful in discriminating old from new words, but not in discriminating List 1 words from List 2 words. Likewise, with plurality discrimination, familiarity should be useful in discriminating same and different plurality words from words that were unrelated to any list word. Contrary to Heathcote et al.'s expectations, this manipulation reduced the fit of the dual process models they considered-ROC curves were less linear. In addition, the estimate of the amount of recollection involved was lower in the conditions without new words than it was in the conditions with new words. 

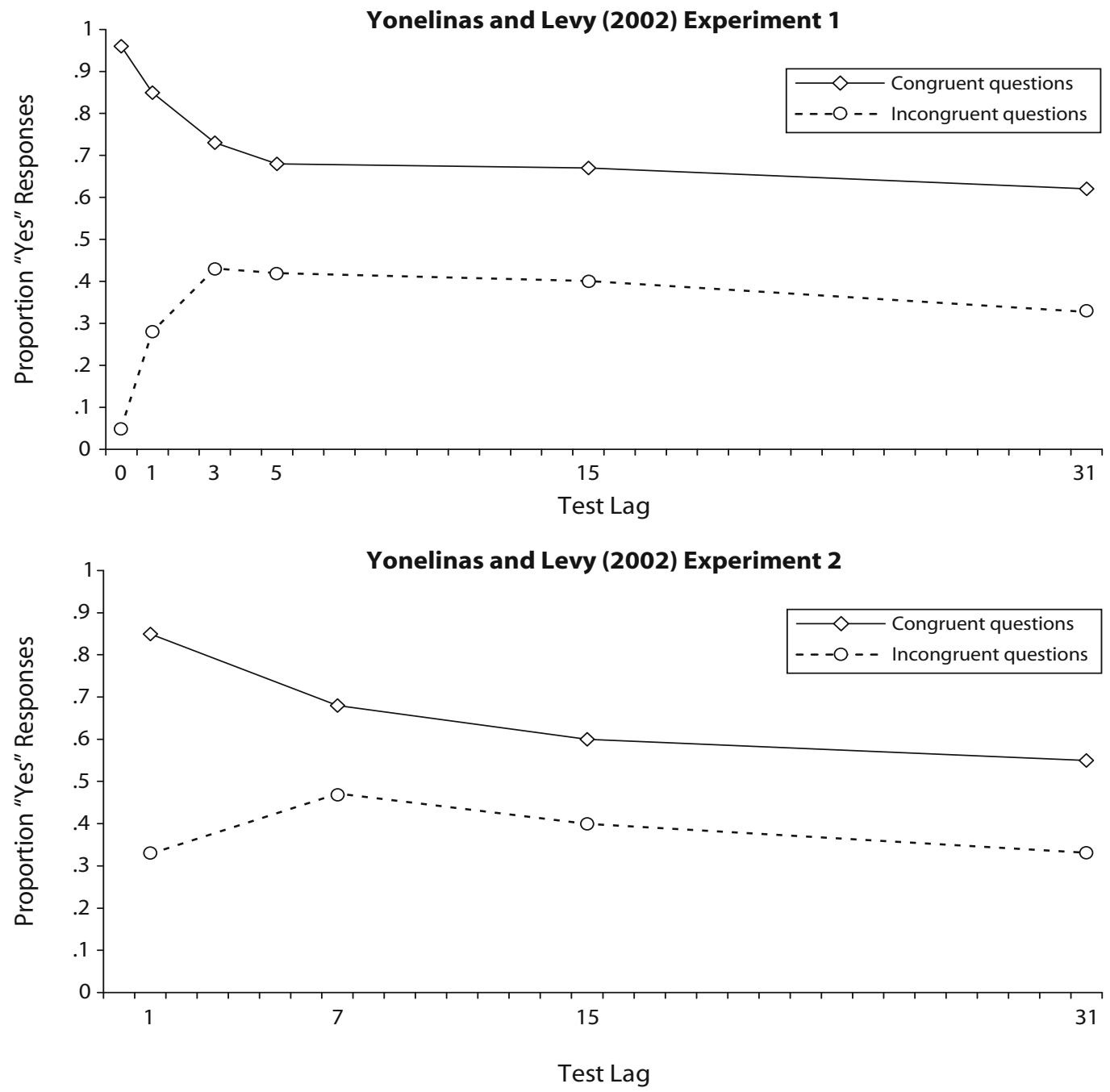

Figure 1. Mean proportion of yes responses as a function of type of question and test lag for Experiments 1 and 2 of Yonelinas and Levy (2002). Note that Yonelinas and Levy's lags here have been altered to correspond to the way lag is defined in our experiments.

Heathcote et al.'s conclusion was that, although an all-ornone form of recollection might exist, there was stronger evidence for the use of continuously graded information in both list discrimination and plurality discrimination.

Humphreys et al. (2003) provided evidence that participants often provide false alarm responses to incongruent test questions, even when the remember/know technique suggests that recollection (which should reduce false alarms) should be present. These results appear to contradict either the assumption that only all-or-none information is involved or the assumption that participants do not falsely recollect the source of old items. After a study session in which half the list items were heard and half were read, Humphreys et al. (2003) presented participants with two test lists (Test 1 and Test 2). On Test 1, participants made remember/know judgments, and on Test 2, they made source monitoring judgments. For the source monitoring judgments, half the participants were instructed to respond "yes" if the words were heard and to respond "no" otherwise. The others were instructed to respond "yes" if the words had been read and to respond "no" otherwise. On Test 2 , they compared the probability of a yes response to congruent questions - those in which the word was heard and the test asked whether it was heard - and incongruent questions - those in which the word was heard and the test asked whether it was read-conditional on a remember response in the first test, with the same probabilities being conditional on a know response. Humphreys et al's (2003) assumption, based on the reasoning behind the process dissociation procedure, was that the response on Test 1 served as an indicator of the type of information that was likely to be present on Test 2. In particular, items that attracted a remember response on Test 1 would be more likely to support recollective experience and less likely to be familiar when tested the second time than items that attracted a know response. Likewise, items that attracted a know response on Test 1 would be more likely to be familiar and less likely to support recollective experience when tested 
the second time. Following this line of reasoning, it was assumed that the presence of recollection on Test 2 should produce a yes response for congruent questions and a no response for incongruent questions. However, the presence of familiarity without recollection on Test 2 should produce a yes response for both congruent and incongruent items. In keeping with these assumptions for congruent questions, the probability of a yes response conditional on a remember response was greater than the probability of a yes response conditional on a know response. However, for incongruent questions, this same inequality held, contradicting the reasoning behind the process dissociation procedure. Instead, it seems necessary to assume that a remember response on Test 1 is an indicator of those items which are most likely to support correct recollection on Test 2 when a congruent question is asked, and most likely to support false recollection when an incongruent question is asked. Alternatively, one could assume that continuously graded information is involved, so that a remember response on Test 1 predicts higher signal strengths for both congruent and incongruent test questions on Test 2.

In order to see how a continuously graded source of information could produce roughly parallel declines in hit and false alarm rates, we will review how global matching models could be applied to these quasicontinuous paradigms (see Clark \& Gronlund, 1996; Humphreys, Pike, Bain, \& Tehan, 1989; Ratcliff, Van Zandt, \& McKoon, 1995). These models match a configural representation of a test pair against memory. With the exception of TODAM (theory of distributed associative memory; Murdock, 1997), this produces a nonzero matching strength for both intact and rearranged pairs. When context is added, these models predict a decline in matching strength for both intact and rearranged pairs as the similarities between the study and test contexts decline. Thus, a decline in the matching strength due to a pair recognition process could explain the decline as a function of test lag for HR and FAR for the Hockley (1991, 1992) results. In the Ratcliff et al. (1995) application of the SAM (search of associative memory) model to source monitoring and list discrimination experiments, there is also a matching strength for both congruent and incongruent questions. Thus, it is also possible that a decline in matching strength could explain the declines in the probability of saying yes to both congruent and incongruent questions in the Yonelinas and Levy (2002) experiments.

In the global matching models, HR and FAR start apart because the contextual match simply multiplies the match of the intact test pair with its memory representation and the sum of the partial matches of the rearranged test pair with the two relevant study pairs. Furthermore, it is assumed that the match of a pair with itself is greater than the sum of two partial matches with pairs having one word in common. As the contextual match declines with lag, the matching strengths gradually come together. One could get a flat function for $d^{\prime}$ in pair recognition because, as lag increases, the variance of the rearranged pair matching strength declines. A similar analysis applies to source monitoring, where it would be assumed that the participant is trying to recognize the color-word pair (see Dennis \& Humphreys, 2001; Ratcliff et al., 1995).
The next question is this: What would happen with a forced-choice test? One's intuition may fail here, because it might seem that, in a forced-choice task, the evidence for the correct alternative would dominate the evidence for the incorrect alternative at short lags, and when memory gets weaker at longer lags, more errors would be made. This may have been Slamecka's (1991) reasoning when he suggested that the use of a forced-choice task would reduce the apparent difference in single-item and pair forgetting rates. In a forced-choice task, however, performance is not just dependent on the difference between the evidence (matching strength) for the two alternatives and the variance of the target and distractor distributions. The correlation between the matching strengths (Clark \& Gronlund, 1996; Hintzman, 1988) must also be taken into consideration. If the HR, FAR, and variance of the target and distractor distributions are all declining, so that there is no change in $d^{\prime}$, there will be no change in performance on a forced-choice test, unless the correlation between target and distractor matching strengths also declines.

We can now see why we should not assume that there is a direct connection between a flat $d^{\prime}$ or forced-choice retention curve and an absence of forgetting. Whenever the flat $d^{\prime}$ or forced choice curve is accompanied by roughly parallel declines in hit and false alarm rates, one must consider the alternative - that both the targets and the distractors are being forgotten. That is, the retention interval affects the signal (target) and noise (distractor) in the same way.

\section{OVERVIEW OF EXPERIMENTS}

In Experiment 1, we replicated Hockley's $(1991,1992)$ item and pair recognition work. In addition, we introduced a manipulation designed to reduce the use of item familiarity in pair recognition. Participants received three successive quasicontinuous item and pair recognition lists. The items used were the same in all three lists, but were randomly assigned to different positions in each list. In this way, participants saw the individual items several times, but in different pairings; thus, in pair recognition decisions, item familiarity should have been perceived as being less informative. It seemed plausible that, under these conditions, participants would be less likely to use item familiarity in pair recognition decisions, relying instead on either recollection or something like the pair matching process (pair familiarity) of the global matching models (see Humphreys, Pike, et al., 1989). If Yonelinas and Levy's (2002) explanation is correct, then FAR to pairs should be flatter by the second or third list, where item familiarity plays less of a role. If, however, the pair FAR is based on participants' false recollections for rearranged pairs or on a pair matching process, then reduced item familiarity by the second or third list should not reduce the decline in the pair FAR curve. This procedure will not work if the use of familiarity is automatic (obligatory), as was originally assumed by Jacoby (1991). However, recent developments have eroded support for this idea of the obligatory use of familiarity. For example, an obligatory process is not compatible with the introduction 
of signal detection assumptions (Yonelinas, 1994, 1999), as it would imply that participants could not alter their criteria for the use of familiarity. Also, there has been a recent trend toward instructing participants in the exclusion conditions of the process dissociation procedure, to respond yes if the item is familiar and there is no recollection (Yonelinas \& Levy, 2002). An obligatory process would not require the use of such instructions.

In Experiment 2, we look at plurality discrimination (Hintzman \& Curran, 1994; Rotello \& Heit, 1999), which can be considered an analogue to the Yonelinas and Levy (2002) source monitoring task. Our intent was to get rid of, or at least reduce, the number of false recollections and/or strong memories associated with an incongruent question, by encouraging participants to also access recollections and/or strong memories associated with a congruent question for the same item. To do this, we asked two questions about each item: For example, having studied the word apple, participants were asked "Was the word apples presented?" and "Was the word apple presented?" If the first question was incongruent, the second question was congruent, and vice versa. The second question was asked as soon as the first question was answered. Our assumption was that the different questions might key the recollection of different information, or that the comparison to the word apples to memory might produce a different match than the comparison to the word apple. Alternatively, the posing of two questions might simply encourage participants to search longer or more extensively.

Regardless of the actual mechanism involved, we thought that if more or better information was being retrieved, we might see an improvement in performance and a difference in the shape of the retention curves. In particular, it might reduce the number of strong but incorrect memories for the incongruent questions, especially at the early lags. The use of two questions does raise a problem about how to score the results. Our solution was to focus on the answer to the second question. Our assumption was that participants would be more likely to integrate the information retrieved from the two queries in answering the second question, and/or the retrieval of more or more relevant information could result from the extra time taken to answer both questions. We also analyzed the answers to the first question, and we report any discrepancies.

In Experiment 3, we look at performance on a verbal discrimination task within a quasicontinuous paradigm because a failure to consider both the signal and the noise had previously led researchers to come to erroneous conclusions about the role of proactive interference (PI) in their respective theories of verbal discrimination learning (Postman \& Keppel, 1977; Underwood, Broder, \& Zimmerman, 1973b). This previous work is relevant to the theoretical position taken in this paper, and verbal discrimination learning may provide an interesting platform for testing ideas about dual processes in recognition.

In verbal discrimination learning, participants are shown a pair of items. One item in each pair is designated the correct alternative. At test, the pair is shown again with the order within the pair randomized. For each test pair, the participant is asked to indicate which item is the cor- rect alternative. It was originally assumed that verbal discrimination learning was similar to animal discrimination learning, in that the participant would learn an approach response to the correct alternative and/or an avoidance response to the incorrect alternative. In contrast, a contemporary researcher might note the similarities with a source monitoring task and assume that recollection (the retrieval of a verbal label) underlies correct responses. However, work that is now largely forgotten shows that neither option is likely (Eckert \& Kanak, 1974; Eckstrand, Wallace, \& Underwood, 1966). Instead, it appears that participants have a strong tendency to rely on the relative frequency with which the members of the pair have been read, rehearsed, and/or pronounced (Eckstrand et al., 1966). Participants tend to rehearse the correct alternative more frequently, and they are often required to articulate their response. Thus, across a series of study and test trials, the frequency of rehearsal of the correct alternative generally increases at a faster rate than does the frequency of rehearsal of the incorrect alternative. A more modern take on the frequency theory of verbal discrimination learning would have the frequency of reading, rehearsing, and pronouncing map onto familiarity.

One of the more dramatic results supporting the frequency theory of verbal discrimination learning comes from Eckstrand et al. (1966), who had participants learn a verbal discrimination list in which the incorrect alternatives were repeated in another pair in which they were, again, incorrect (the both wrong condition). When incorrect alternatives are repeated, participants have two opportunities to learn an avoidance response or to learn the "incorrect" label, and two learning opportunities should be better than one. However, performance in the both wrong condition was substantially worse than in the control condition, where no items were repeated. This finding, in conjunction with the results of transfer studies and studies in which the frequency of the items within a pair was directly manipulated, convinced most researchers that the frequency theory of verbal discrimination learning was largely correct. The exceptions involved some infrequently used, alternate ways in which participants learn verbal discrimination lists. This literature therefore suggests that recollection is unlikely to play a role in verbal discrimination.

We assume that, if the verbal discrimination task is used in a quasicontinuous paradigm, the correct alternative at test will be more familiar than the incorrect alternative. As lag increases, the familiarity measures of both the correct and incorrect alternatives will decline together, producing little or no change in $d^{\prime}$. To see why we anticipate a flat retention curve, consider the following thought experiment in which frequency is manipulated. Use a quasicontinuous design where some items are presented twice, and some once. For the twice-presented items, calculate the lag from the second presentation, and for the oncepresented items, calculate the lag from the only presentation. Based on previous work on single-item recognition in a quasicontinuous paradigm, the probability of saying "yes" to both twice- and once-presented items will decline as a function of lag (Hockley, 1982). Calculate $d^{\prime}$ by 
considering yes responses to twice-presented items as hits and yes responses to once-presented items as false alarms. The result will be a relatively flat forgetting curve, at least over some portion of the range, despite our knowledge that the underlying information is declining. In the verbal discrimination test, the correct alternative corresponds to the twice-presented item and the incorrect alternative to the once-presented item, since the correct alternative is assumed to be rehearsed more. Our third experiment was therefore designed to demonstrate another situation in which stable retention functions might be found, despite having reason to believe that the underlying information was declining.

\section{EXPERIMENT 1}

In Experiment 1, participants received three lists in which study trials were word pairs and test probes were either single words or word pairs. The three lists each contained the same word stimuli, with words being randomly assigned to different positions in each list, such that no two words were paired together in more than one list, the aim being to increase the general familiarity of the individual words across the lists. In doing this, we anticipated that participants would be less likely to rely on item familiarity in making pair decisions - participants were explicitly informed about the repetition of the items - and, by List 3, would demonstrate pair recognition trends less influenced by item familiarity, if item familiarity had been influencing pair recognition responses. Note that using item familiarity to discriminate between intact and rearranged pairs could only hurt performance. Therefore, we only needed participants to be aware that basing pair decisions on item familiarity would not be useful, and, accordingly, to try to reduce their use of it. We should not have to totally eliminate any familiarity difference between the shortest and longest lags. Provided the use of familiarity is not automatic (as discussed previously), and if Yonelinas and Levy's (2002) explanation is correct, pair FAR should be flatter by the second or third list. If item familiarity is not responsible for the pair FAR decline, however, this curve should continue to show a decline across lag in the second and third lists.

\section{Method}

Participants. Thirty first-year psychology students from the University of Queensland served as participants in the experiment and received course credit for doing so. All participants completed the three lists in a single session.

Design. The experiment used a 3 (list: first, second, third) $\times 2$ (test type: item recognition, pair recognition) $\times 5$ (lag: 1, 2, 4, 8, 16) within-subjects design. HR, FAR, and $d^{\prime}$ estimates were dependent variables. A quasicontinuous recognition procedure was employed.

Materials. Three lists were constructed, with the position of study and test trials varying across the lists. The same words were used in each list, but were randomized for each list, so that the positions of words differed across lists and no two words were paired in more than one list. Also, words could serve as new test items in one list while being study items (and subsequently old test items) for other lists. There were 366 high-frequency (60-250 occurrences per million words), four- to six-letter real words taken from the SMH Word Database (Dennis, 1995) in each of the three lists. High-frequency words were chosen because pair recognition is typically better when lists are composed only of high-frequency stimuli (Clark, 1992), and this arrangement served to safeguard against possible floor effects, which might have otherwise given the illusion of nondeclining curves. Stimuli were presented to participants in lowercase, black, 24-point MS sans serif font strings on a gray background. Participants indicated their responses by clicking on response boxes labeled old and new within the onscreen interface, using a mouse.

Each list consisted of 163 paired-item study presentations, 80 single-item recognition tests, and 80 pair recognition tests. The paired items for the study presentations were formed by randomly selecting items from the stimulus pool without replacement for each participant. Of the 80 single-item recognition tests, 40 were entirely new items selected at random from the stimulus pool (new) that had not been presented as part of any study pair. The other 40 test items were selected from study pairs previously presented (old). Half of the old test items came from the left and half from the right positions of study pairs. For the 80 pair recognition tests, 40 were intact test pairs (old), exactly the same as previously studied pairs, whereas the other 40 were rearranged test pairs (new) consisting of new pairings of previously presented study pair items. Half of the rearranged pairs were constructed by pairing the left member of a study pair with the right member of the immediately preceding pair, whereas the other half were constructed by pairing the right member of a study pair with the left member of the immediately preceding pair. This was done to equate, as nearly as possible, the list position - and hence familiarity - of the individual items in each test pair. Further, the left-right study position of individual items was always maintained for both intact and rearranged test pairs.

Test lag (retention interval) was varied over the five levels of 1 , $2,4,8$, and 16. Lag was calculated as the number of intervening presentations, both study and test, between a given study pair and its corresponding test, except for rearranged test pairs, for which lag was calculated from the second of the two study pairs used to make up the test pair. There were eight tests of old items, intact pairs, and rearranged pairs at each level of test lag. No lag existed for new test items, since these had not been previously presented. Lists were constructed by interspersing tests among the study pairs in a nonsystematic, random-like manner, with the first three study presentations of each list never being tested, in order to avoid list primacy effects.

Procedure. Participants were fully informed about the nature of the experiment and about each type of test they would receive. The order in which participants received each list was fully counterbalanced, so that any difference across the lists could not be attributed to sequencing effects. Between lists, participants were instructed that the tests in the following section (list) were specific to study items presented within that section, despite the same words appearing across sections, and that they should consider each section of the experiment as being separate. Study pairs were presented for $3,000 \mathrm{msec}$ on a single line in the center of the computer screen, with approximately $10 \mathrm{~mm}$ separating the items. There was a $500-\mathrm{msec}$ blank interval between presentations. Test probes (both single items and pairs) were similarly presented in the center of the screen, but were distinguished by the addition of two boxes, one labeled old and the other labeled new, in the lower central portion of the screen. Participants used a mouse to click on one of the boxes to indicate whether they believed the test stimulus had been previously presented (old) or not (new). The test probe remained on the screen until a response was made. In total, sessions lasted about $55 \mathrm{~min}$.

\section{Results and Discussion}

Discrimination $\left(d^{\prime}\right)$ analysis. Recognition accuracy across the three lists was assessed by analyzing $d^{\prime}$ estimates (see Figure 2). In this and in the subsequent study, false alarm rates of .00 were replaced with $1 /(2 n)$, and hit rates of 1.00 were replaced with $1-1 /(2 n)$, where $n$ is the number of tests per lag (Snodgrass \& Corwin, 1988). 

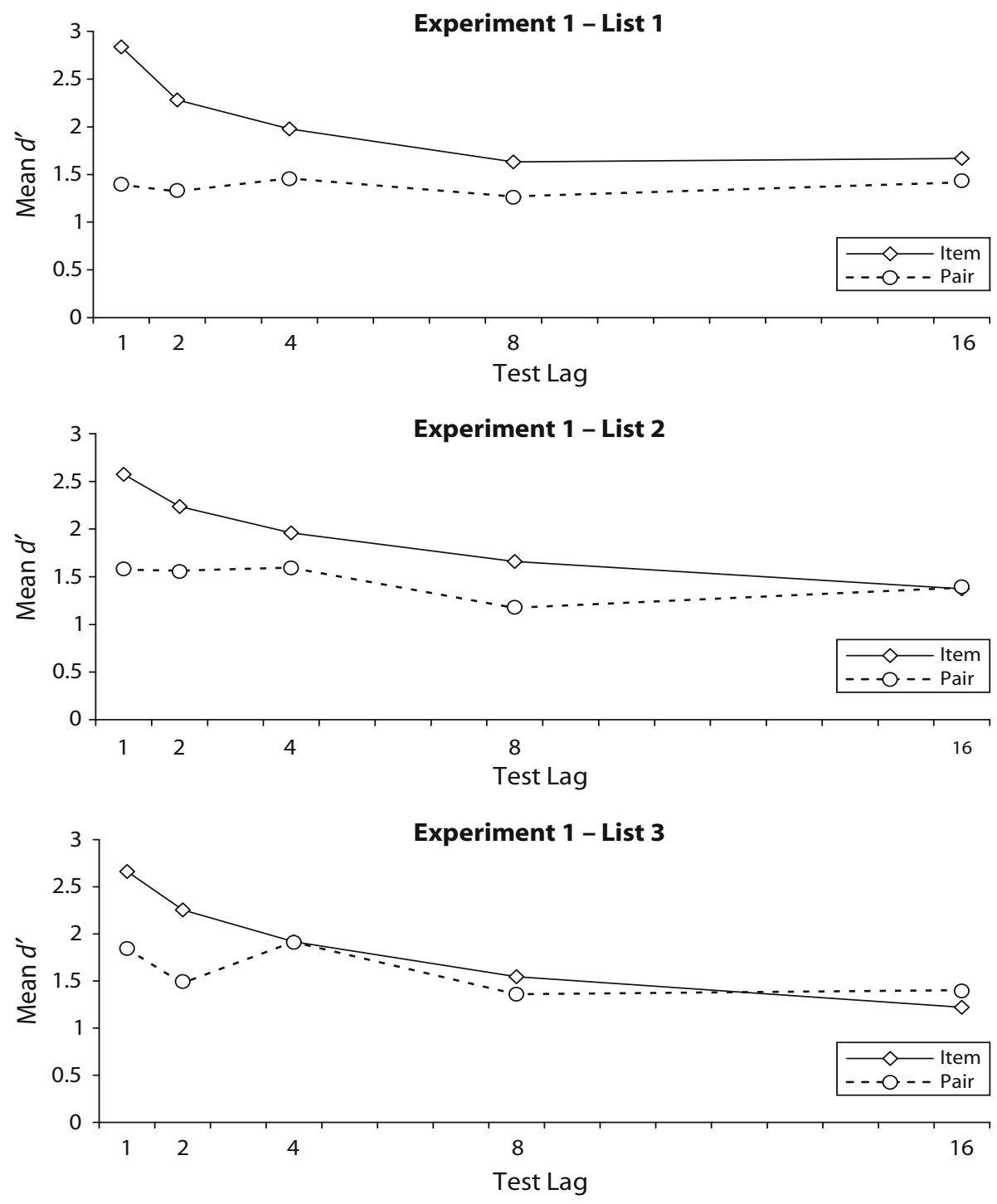

Figure 2. Recognition accuracy, as assessed using $d^{\prime}$ for single item and pair recognition as a function of test lag across lists for Experiment 1.

A $3 \times 2 \times 5$ repeated measures ANOVA was conducted with list, test type, and test lag as the independent variables and $d^{\prime}$ as the dependent variable. This revealed a main effect for test type $\left[F(1,29)=16.206, M S_{\mathrm{e}}=3.596\right.$, $\left.p<.001, \eta_{\mathrm{p}}^{2}=.358\right]$, indicating that, overall, $d^{\prime}$ for single items was greater than $d^{\prime}$ for pairs $(M \mathrm{~s}=1.987$ and 1.478 , respectively). There was a main effect for test lag $\left[F(4,116)=32.163, M S_{\mathrm{e}}=.535, p<.001, \eta_{\mathrm{p}}^{2}=.526\right]$, indicating a significant decline in $d^{\prime}$ across levels of lag, and a significant interaction was found between test type and test lag $\left[F(4,116)=14.141, M S_{\mathrm{e}}=.580, p<.001\right.$, $\left.\eta_{\mathrm{p}}^{2}=.328\right]$. This interaction was due to a decline in $d^{\prime}$ for item recognition and a relatively stable $d^{\prime}$ for pair recognition. There was also a significant interaction between list and test type $\left[F(2,58)=4.193, M S_{\mathrm{e}}=.661, p=.020\right.$, $\left.\eta_{\mathrm{p}}^{2}=.126\right]$, due to a successive decrease in the difference between item $d^{\prime}$ and pair $d^{\prime}$ across the first list $(M \mathrm{~s}=$ 2.079 and 1.375 , respectively), second list $(M \mathrm{~s}=1.961$ and 1.459 , respectively), and third list ( $M \mathrm{~s}=1.920$ and 1.600 , respectively). Overall, $d^{\prime}$ for items showed a trend toward becoming poorer across the three lists, whereas $d^{\prime}$ for pairs showed a trend toward improving.

Hit rates and false alarm rates. Figure 3 shows item and pair HR and FAR across lag for each list. To determine whether HR changed across lists, a $3 \times 2 \times 5$ repeated measures ANOVA was conducted with list, test type, and test lag as the independent variables and HR as the dependent variable. Here, there was a significant effect of test lag $\left[F(4,116)=61.977, M S_{\mathrm{e}}=.044, p<.001, \eta_{\mathrm{p}}^{2}=.681\right]$, indicating that, overall, HR declined across test lag. There was also a significant interaction between test type and test $\operatorname{lag}\left[F(4,116)=2.577, M S_{\mathrm{e}}=.021, p=.041, \eta_{\mathrm{p}}^{2}=.082\right]$, owing to the decline across lag for pair HR being slightly less monotonic than that for item HR. No other main effects or interactions were significant, suggesting that HR was not influenced by the number of lists received. 

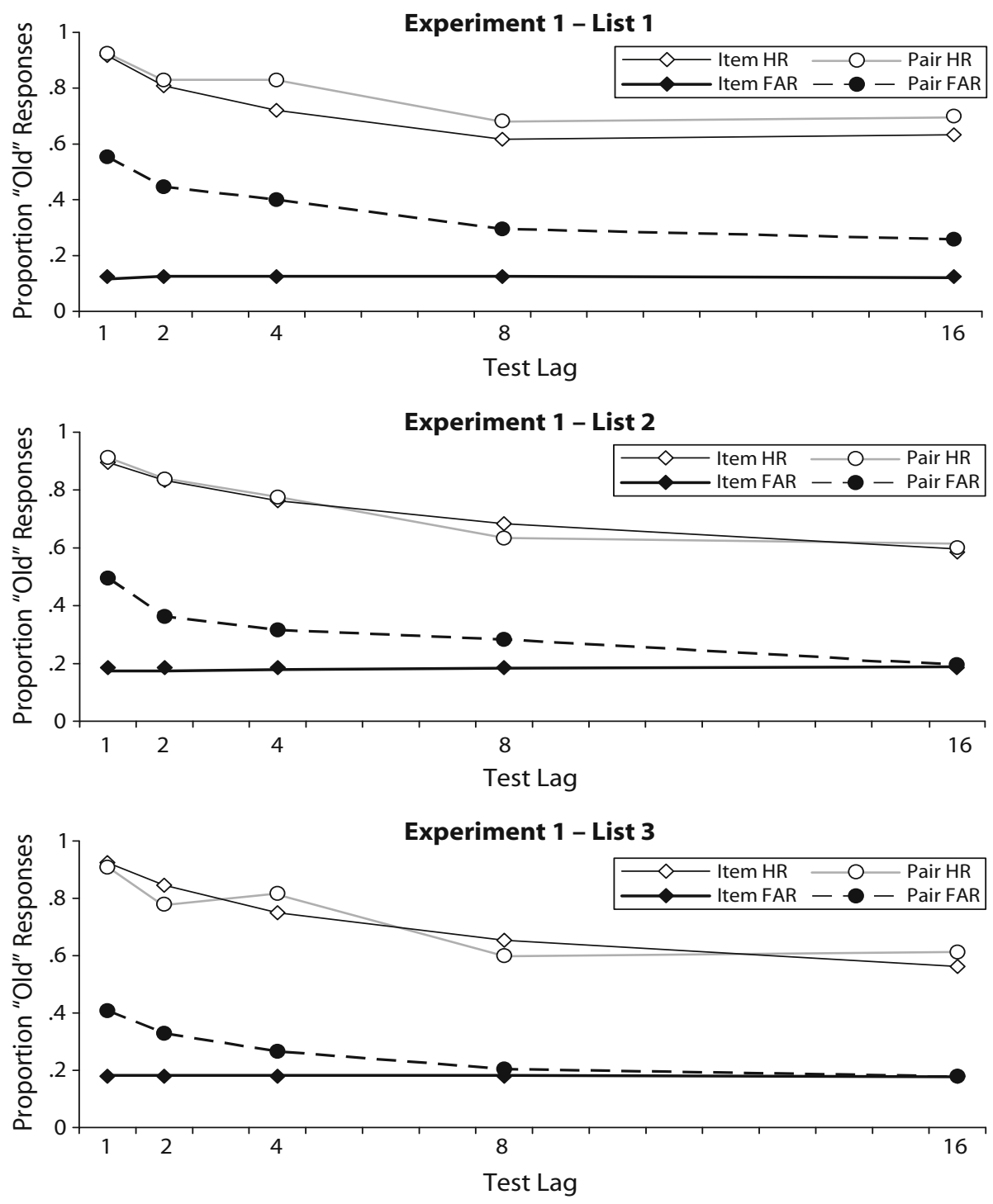

Figure 3. Mean hit and false alarm rates for item and pair recognition as a function of test lag across lists for Experiment 1.

In examining FAR trends over levels of lag across the lists, only pair FAR can be considered, since item FAR is based on new items and has no test lag. A $3 \times 5$ repeated measures ANOVA with list and test lag as independent variables and pair FAR as the dependent variable showed that there was a significant main effect for list $[F(2,58)=$ $\left.11.704, M S_{\mathrm{e}}=.041, p<.001, \eta_{\mathrm{p}}^{2}=.228\right]$, indicating that pair FAR decreased across lists. Repeated contrasts indicated that pair FAR declined between the first and second lists $\left[F(1,29)=7.167, M S_{\mathrm{e}}=.015, p=.012, \eta_{\mathrm{p}}^{2}=.198\right]$, and again between the second and third lists $[F(1,29)=$ $8.543, M S_{\mathrm{e}}=.010, p=.007, \eta_{\mathrm{p}}^{2}=.228 ; M \mathrm{~s}=.391, .331$, and .278 , respectively]. There was also a main effect for test lag $\left[F(4,116)=27.002, M S_{\mathrm{e}}=.038, p<.001, \eta_{\mathrm{p}}^{2}=\right.$ $.482]$, suggesting that the decline across lag was significant. There was no interaction, however, between list and test lag $(F<1)$, indicating that, although pair FAR did decline across test lag, the way in which it declined was consistent across the three lists.

To determine the nature of the single-item FAR across the three lists, a one-way repeated measures ANOVA was conducted with list as the independent variable and item FAR as the dependent variable. This revealed that there was a main effect of list $\left[F(2,58)=5.088, M S_{\mathrm{e}}=.007\right.$, $\left.p=.009, \eta_{\mathrm{p}}^{2}=.149\right]$, which repeated contrasts showed to be due to a significant increase in item FAR between Lists 1 and $2\left[F(1,29)=7.345, M S_{\mathrm{e}}=.015, p=.011\right.$, $\left.\eta_{\mathrm{p}}^{2}=.202\right]$, with no difference between Lists 2 and 3 $[F<1, M \mathrm{~s}=.125, .186$, and .179 , respectively].

Because of the repetition of items across lists, it was felt that participants would be least likely to base pair judgments on item familiarity in List 3 . We wanted to see whether there was still a declining pair HR and FAR in that list, as had originally been found by Hockley (1991, 
1992). We conducted a $2 \times 5$ repeated measures ANOVA with pair test type (intact vs. rearranged pairs) and test lag as independent variables and the probability of an old response (giving a pair HR and FAR) as the dependent variable. There was a significant effect of pair test type $\left[F(1,29)=92.858, M S_{\mathrm{e}}=.175, p<.001, \eta_{\mathrm{p}}^{2}=762\right]$, such that, overall, HR was considerably higher than overall FAR $(M \mathrm{~s}=.743$ and .278 , respectively). The decline across lag was significant $\left[F(4,116)=23.561, M S_{\mathrm{e}}=.032, p<\right.$ $\left..001, \eta_{\mathrm{p}}^{2}=.448\right]$. The interaction between pair test type and lag did not reach significance, however $[F(4,116)=$ $\left.2.215, M S_{\mathrm{e}}=.024, p=.072, \eta_{\mathrm{p}}^{2}=.071\right]$, indicating that, in general, both HR and FAR declined across lag and did so in a similar manner.

In sum, the results from Experiment 1 support the assumption that giving participants three successive lists - all with the same stimuli, but randomized across lists - may increase general item familiarity and hence reduce reliance on item familiarity in pair recognition tests. Results of $d^{\prime}$ analyses indicated that this did occur, in that, overall, item recognition performance tended to decline across lists (presumably because all items were becoming more familiar, so more false alarms were being made), whereas, overall, pair recognition performance tended to improve across lists (presumably because item familiarity was being relied on less, so fewer pair false alarms were being made). Importantly, the decreasing trend in single item $d^{\prime}$ and the increase in item FAR cannot be attributed to participant boredom or fatigue since there was an increasing trend in pair $d^{\prime}$ and a decrease in pair FAR. The overall increase in pair $d^{\prime}$ across lists could possibly be attributed to learning to learn; however, it is surprising that, if learning to learn were occurring, the effect should show up in a decline in the pair FAR without there being an increase in the pair HR. Furthermore, learning to learn cannot explain the increase in the single-item FAR from List 1 to List 2 . Thus, it appears that item familiarity was increased by the reuse of items across the three lists and that item familiarity was involved in pair recognition decisions, at least in List 1, prior to its apparent usefulness being reduced. Following this, participants made successively fewer pair false alarms across lists.

The tendency for pair FAR to drop across lists does suggest that item familiarity may be present in pair recognition. However, the fact that the three lists showed parallel declines in pair FAR across lag suggests that item familiarity may not be responsible for such a declineparticularly since there was still a significant decline in both pair HR and pair FAR in List 3. This indicates that, even with a reliance on item familiarity reduced, pair FAR still declines across lag, so stable pair retention is found even in List 3. It seems unlikely, therefore, that a rapid loss of item familiarity is responsible for the decline in pair FAR, as proposed by Yonelinas and Levy (2002).

\section{EXPERIMENT 2}

In Experiment 2, we considered a plurality discrimination task (Hintzman \& Curran, 1994; Rotello \& Heit, 1999). We believed this should be another situation in which participants would show roughly parallel declines in the probability of responding "yes" to both congruent and incongruent questions across lag, similar to the declines reported by Yonelinas and Levy (2002), using a source monitoring task. However, we included a condition to test the Yonelinas and Levy explanation: If we consider that it is possible for participants to have false recollections and/or strong memories associated with an incongruent question about an item, we may be able to reduce erroneous responses based on these by encouraging the participants to also consider correct recollections and/or strong memories associated with a congruent question for the same item. That is, we may be able to improve memory performance by getting participants to consider both congruent and incongruent questions, as opposed to just one or the other. Thus, when one question is asked of participants, we would expect to see declines in both congruent and incongruent question curves across lag-possibly in parallel. This would be the case under both the Yonelinas and Levy explanation, where yes responses to incongruent questions result from familiarity, and our explanation, where they result from false recollections or strong incongruent question matches with memory. When two questions are asked, however, predictions should differ. Under the Yonelinas and Levy explanation, we would expect to see a similar pattern of results as when one question is asked, since familiarity should not change for the item due to two questions being asked. For our explanation, we would expect improved memory performance in the form of improved overall sensitivity and a reduction in the number of yes responses to incongruent questions - especially at the shortest lags_-since participants should consider more, or more relevant, information.

When participants are asked a single question (congruent or incongruent) at test, they can search for both confirmatory and disconfirmatory evidence, or they may attempt to match the test information, as well as its alternative, with information stored in memory. Having done this, they can choose the strongest match. It may not always be the case, however, that participants are so thorough; in reality, many may simply limit their decision by considering only the information retrieved for the test question. Consider a study item, such as apple, which is followed by the test item apples. At a short lag, the match could be quite strong, reflecting both a basic similarity between apple and apples and the strong contribution of the temporal component from the study trial; hence, the participant may false alarm. However, the match between apple and apple should be even stronger. If this match is considered together with the match between apple and apples, then more accurate responses should be given. Thus, if two questions are asked (as opposed to only one), the participant may be able to avoid false alarms - especially at the shorter lags. They may be able to improve their overall ability to discriminate between congruent and incongruent questions.

Experiment 2 consisted of two between-subjects conditions: a one-question condition and a two-question condition. Participants studied nouns in either the singular or plural form. In the one-question condition, they were asked 
a single question about a study event in each test trial. That is, they were presented with either the singular or plural form of a studied noun and asked whether the item occurred in the study list in the same form. The test question was either congruent with (e.g., study apple, test apple) or incongruent with (e.g., study apple, test apples) the form of the study item. Participants in the two-question condition were asked two questions, one after the other, about each test item. If the first question was congruent, then the second question was incongruent, and vice versa.

For the one-question condition, we expected the pattern of results to be similar to that observed by Yonelinas and Levy (2002) in their source monitoring task. That is, yes responses to both congruent and incongruent questions should decline across lag, possibly in parallel. For the two-question condition, where participants should be using more available information or more useful information to inform their decisions, we expected the pattern of results to differ. We had three specific predictions: (1) We expected that, relative to the one-question condition, the decline in yes responses to congruent and incongruent questions (as found by Yonelinas \& Levy, 2002) would be attenuated. (2) We predicted that participants in the two-question condition would be more sensitive to the prospect of falsely endorsing an incongruent question than those in the one-question condition. Thus, for two-question participants, in comparison with one-question participants, we expected to see a reduction in the probability of falsely endorsing an incongruent test item, with little change in the probability of falsely endorsing a new test item. (3) We predicted that, if the second question were to lead participants to retrieve additional or better quality information, their ability to discriminate between congruent and incongruent test questions should improve, resulting in an improved sensitivity estimate.

\section{Method}

Participants. Forty participants took part in the experiment. All had responded to an advertisement at the university campus and were paid a small sum of money for their time. Most participants were undergraduate students at the University of Queensland. There were 20 participants in the one-question condition and 20 in the two-question condition.

Design. This experiment was a quasicontinuous plurality discrimination procedure with a mixed factorial design. The number of questions (one or two) participants received was a between-subjects variable, and test lag was a within-subjects variable. Study and test word presentations were intermixed, and five levels of lag were tested: $2,4,8,16$, and 32 . Half of the study words were nouns presented in singular form, and the other half were nouns presented in plural form. Participants in the two-question condition were asked both a congruent and an incongruent question [e.g., "Was the word below previously presented? (apple)," and "Was the word below previously presented? (apples)," when they had earlier been presented with apple). For half the tests, the congruent question was asked first, and for the other half, the incongruent question was asked first. In the one-question condition, only the first question was asked, followed by a filler screen on which the test word was again presented, and participants were required to click on a "continue" button. This was done to ensure comparability of lags across the two conditions. New words that had not previously been presented in either singular or plural form were also tested throughout the list.

Materials and Procedure. The stimuli were four- to eight-letter nouns of intermediate frequency (20-50 occurrences per million words) selected from the SMH Word Database (Dennis, 1995). There were 650 list trials, including 362 study trials and 288 test trials (48 tests at each level of lag, and 48 new item tests). All words were presented in lowercase, black, 24-point MS sans serif font in the center of the computer screen. Study words were nouns presented in singular or plural form, randomized for each participant.

Participants were fully informed of the nature of the experimental task prior to commencing the experiment. For the test trials, they were instructed to use the mouse to click yes if they were confident that the test word had been presented in the indicated plurality, no if they were confident that the test word had not been presented in the indicated plurality, and unsure if they were uncertain.

Each study word remained on the screen for 2,000 $\mathrm{msec}$ and was replaced by a $200-\mathrm{msec}$ blank screen before the next trial, whereas test words remained on the screen until the participant made a response. In the two-question condition, each test trial comprised two response-dependent screens, with the test question in the upper portion of the screen, the test word in the center of the screen, and the response buttons (yes, unsure, no) in the lower portion of the screen. On half of the test trials, the singular form of the noun was asked first; on the other half, the plural form was asked first. In the onequestion condition, only the first test question was asked. In total, sessions tended to last about $40 \mathrm{~min}$.

\section{Results}

Confidence rating calculations. In calculating mean confidence ratings for each question type, yes responses were assigned a value of 1 , unsure responses a value of 0.5 , and no responses a value of 0 . This scoring scheme provides a measure of how confident the participant was that the test item was presented at study in the form shown. Thus, the average confidence level for a congruent item can be likened to an HR, and the average confidence level for an incongruent item can be likened to a FAR. These values were averaged for each level of lag across each question type to provide a mean confidence rating for congruent and incongruent questions at the varying retention intervals. For the two-question condition, only responses to the second question are included in the main analyses, since it is at this point that both types of information are likely to have been considered. We do, however, elaborate on analyses for which only responses to the first question are considered. Mean confidence ratings for each condition as a function of question type and lag are shown in Figure 4.

One-question condition confidence ratings. To examine the mean confidence ratings in the one-question condition, a 2 (question type: congruent or incongruent) $\times 5$ (lag: $2,4,8,16$, or 32 ) repeated measures ANOVA was conducted. This showed a significant main effect for question type $\left[F(1,19)=38.767, M S_{\mathrm{e}}=.126, p<.001\right.$, $\left.\eta_{\mathrm{p}}^{2}=.671\right]$, a significant main effect for lag $[F(4,76)=$ $\left.25.201, M S_{\mathrm{e}}=.008, p<.001, \eta_{\mathrm{p}}^{2}=.570\right]$, and a significant interaction between question type and lag $[F(4,76)=$ $\left.3.956, M S_{\mathrm{e}}=.006, p=.006, \eta_{\mathrm{p}}^{2}=.172\right]$. For congruent questions, mean confidence ratings declined significantly across the five levels of lag $\left[F(4,76)=25.599, M S_{\mathrm{e}}=\right.$ $\left..006, p<.001, \eta_{\mathrm{p}}^{2}=.574\right]$. Helmert contrasts revealed that the mean confidence rating at Lag 2 was significantly greater than that at subsequent lags $[F(1,19)=43.908$, $\left.M S_{\mathrm{e}}=.011, p<.001, \eta_{\mathrm{p}}^{2}=.698\right]$, and similarly for Lag 4 $\left[F(1,19)=34.481, M S_{\mathrm{e}}=.005, p<.001, \eta_{\mathrm{p}}^{2}=.645\right]$, and $\operatorname{Lag} 8\left[F(1,19)=19.650, M S_{\mathrm{e}}=.009, p<.001, \eta_{\mathrm{p}}^{2}=\right.$ 

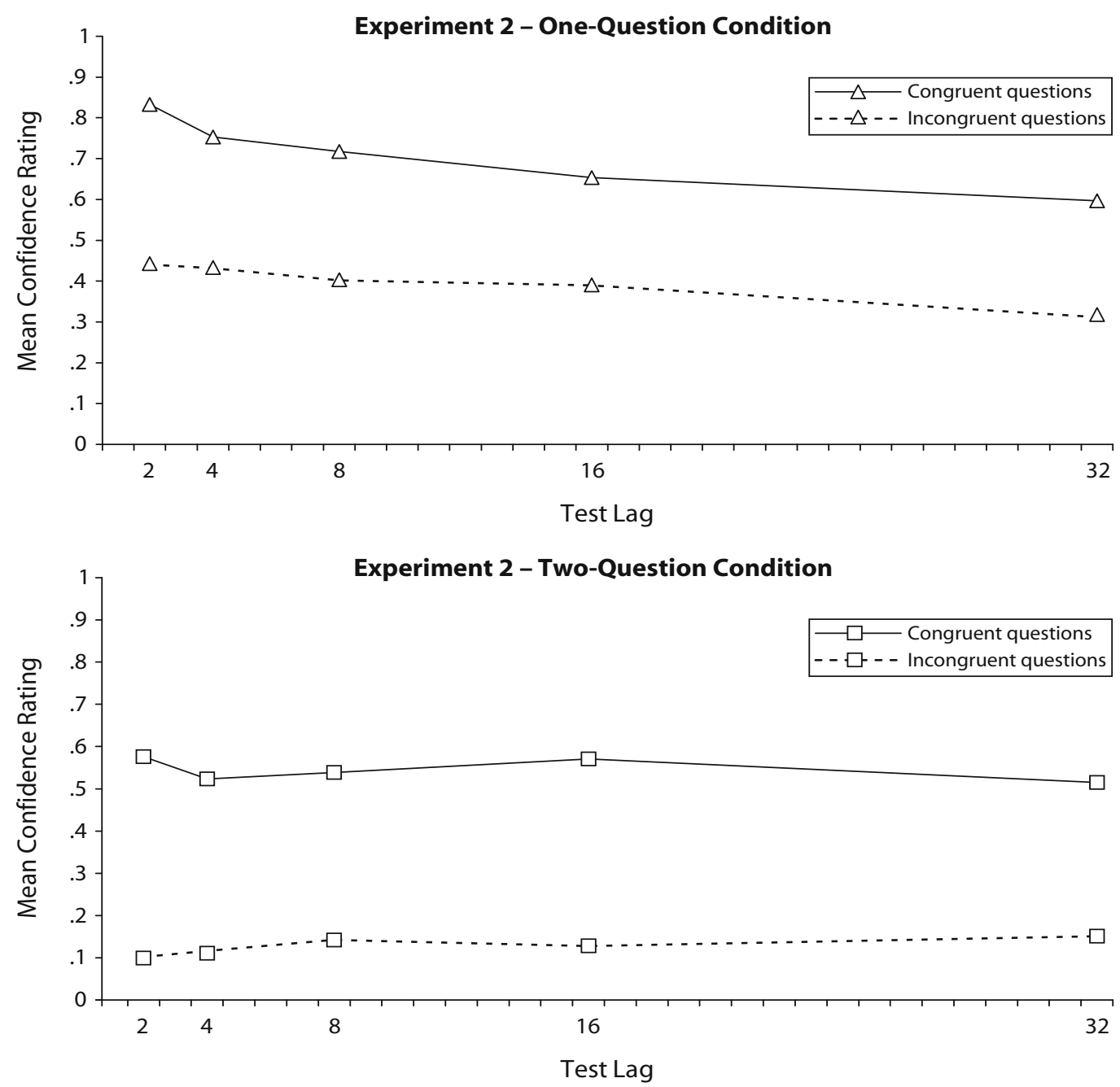

Figure 4. Mean confidence ratings as a function of question type and test lag in the one-question and two-question conditions of Experiment 2.

.508], and that that at Lag 16 came very close to being significantly greater than that at $\operatorname{Lag} 32[F(1,19)=4.314$, $\left.M S_{\mathrm{e}}=.015, p=.052, \eta_{\mathrm{p}}^{2}=.185\right]$. For incongruent questions, mean confidence ratings also declined significantly across the five levels of lag $\left[F(4,76)=6.826, M S_{\mathrm{e}}=.007\right.$, $\left.p<.001, \eta_{\mathrm{p}}^{2}=.264\right]$. Helmert contrasts showed that the mean confidence rating at Lag 2 was significantly greater than that at subsequent lags $\left[F(1,19)=5.422, M S_{\mathrm{e}}=\right.$ $\left..012, p=.031, \eta_{\mathrm{p}}^{2}=.222\right]$, and that the same was true for Lag $4\left[F(1,19)=8.686, M S_{\mathrm{e}}=.009, p=.008, \eta_{\mathrm{p}}^{2}=\right.$ $.314]$, Lag $8\left[F(1,19)=4.840, M S_{\mathrm{e}}=.010, p=.040\right.$, $\left.\eta_{\mathrm{p}}^{2}=.203\right]$, and Lag $16\left[F(1,19)=9.181, M S_{\mathrm{e}}=.012\right.$, $\left.p=.007, \eta_{\mathrm{p}}^{2}=.326\right]$. Thus, for both congruent and incongruent question curves, there was nearly always a decline across the full range of lags.

Two-question condition confidence ratings. Another repeated measures ANOVA was conducted on the two-question condition data. This showed a significant main effect for question type $\left[F(1,19)=58.142, M S_{\mathrm{e}}=\right.$ $\left..151, p<.001, \eta_{\mathrm{p}}^{2}=.754\right]$. There was no main effect for lag $(F<1)$, but the interaction between question type and lag was significant $\left[F(2.323,44.136)=3.575, M S_{\mathrm{e}}=\right.$ $\left..009, p=.030, \eta_{\mathrm{p}}^{2}=.158\right]$. The degrees of freedom for the interaction between question type and lag were reduced using a Greenhouse-Geisser correction due to a failure of the variances of difference scores to meet the assumption of sphericity [Mauchly's $W(14)=.297, p=$ .012]. In investigating this interaction, we found mean confidence ratings for congruent questions to be stable across lag $\left[F(4,76)=1.558, M S_{\mathrm{e}}=.010, p=.194, \eta_{\mathrm{p}}^{2}=\right.$ .076], whereas mean confidence ratings for incongruent questions showed a significant increase $[F(4,76)=2.816$, $\left.M S_{\mathrm{e}}=.003, p=.031, \eta_{\mathrm{p}}^{2}=.129\right]$. Helmert contrasts revealed that the mean confidence rating for incongruent questions at Lag 2 was significantly lower than that at all subsequent lags $\left[F(1,19)=4.496, M S_{\mathrm{e}}=.005, p=\right.$ $\left..047, \eta_{\mathrm{p}}^{2}=.191\right]$, and that the mean confidence rating at Lag 4 was marginally lower than that at subsequent lags $\left[F(1,19)=3.381, M S_{\mathrm{e}}=.005, p=.082, \eta_{\mathrm{p}}^{2}=.151\right]$. Mean incongruent question confidence ratings did not 
differ, however, from Lag 8 onward. Thus, for the twoquestion condition, although the congruent question curve was flat, the incongruent question curve showed some increase across initial lags before becoming flat.

Comparison of types of false alarm. A $2 \times 2$ mixed factorial ANOVA was conducted to examine participants' confidence ratings for having seen incongruent tests versus new tests. Confidence ratings were collapsed across levels of test lag for incongruent questions and compared with confidence ratings for new test items from each of the conditions. For the two-question condition, only responses to the second question were included. This showed a significant difference between confidence ratings for incongruent versus new tests $[F(1,38)=63.072$, $\left.M S_{\mathrm{e}}=.007, p<.001, \eta_{\mathrm{p}}^{2}=.624\right]$, a significant difference across the one- and two-question conditions $[F(1,38)=$ $\left.25.250, M S_{\mathrm{e}}=.020, p<.001, \eta_{\mathrm{p}}^{2}=.399\right]$, and, importantly, a significant interaction between question condition and test type $\left[F(1,38)=35.486, M S_{\mathrm{e}}=.007, p<\right.$ $\left..001, \eta_{\mathrm{p}}^{2}=.483\right]$. Using pairwise comparisons to investigate this interaction, we revealed that there was no significant difference in confidence ratings to new questions across the one- and two-question conditions $[t(38)=$ $1.453, p=.155 ; M \mathrm{~s}=.135$ and .089 , respectively], but that confidence ratings to incongruent questions in the one-question condition were significantly higher than those in the two-question condition $[t(24.928)=6.592$, $p<.001 ; M \mathrm{~s}=.397$ and .126 , respectively]. In the latter analysis, the degrees of freedom were adjusted when Levene's test showed unequal variances across the two groups $(F=11.037, p=.002)$.

Discrimination $\left(d^{\prime}\right)$ analysis. A $2 \times 5$ mixed factorial ANOVA was conducted on values of $d^{\prime}$. These were calculated by treating a yes response as indicating the participant's confidence in having previously seen the test stimulus, and both unsure and no responses as indicating the participant's lack of confidence in having seen the test stimulus (unsure responses were treated as no responses). This choice of a cut-off between yes and no responses was based on the fact that extant theories either predict no difference as a function of where the cutoff is chosen (Donaldson, 1996), or they predict a greater discriminability at the higher cutoff because more of the familiarity-based responses are excluded (Jacoby, 1991; Yonelinas, 1999). As with previous analyses, for the two-question condition, only the answers to the second question were considered. The trends for these analyses trends are displayed in Figure 5. We found a significant main effect for lag $\left[F(3.156,119.919)=3.437, M S_{\mathrm{e}}=.236, p=.017, \eta_{\mathrm{p}}^{2}=\right.$ .083], where degrees of freedom were reduced because of the need for a Greenhouse-Geisser correction [Mauchly's $W(14)=.594, p=.026]$. A significant main effect for condition $\left[F(1,38)=5.201, M S_{\mathrm{e}}=.590, p=.028, \eta_{\mathrm{p}}^{2}=\right.$ $.120]$ showed that overall sensitivity was better in the twoquestion condition $(M=1.495)$ than in the one-question condition $(M=.941)$. The lag $\times$ condition interaction was not significant.

When these analyses were run using only the first question (as opposed to the second) from the two-question condition, findings for both the one- and two-question conditions became very similar. Confidence ratings for both congruent and incongruent questions declined across lag, there was no difference in confidence ratings for incongruent tests across the two conditions, and the main effect for condition in the $d^{\prime}$ analysis became nonsignificant. This may indicate that the retrieval of more or more relevant information does not occur in this task until the second question is asked.

\section{Discussion}

We had three predictions about the differences between the one-question and two-question conditions in this experiment: (1) The decline in the HR and FAR would be reduced in the two-question condition, in relation to that in the one-question condition. As predicted, there were significant and roughly parallel declines in both HR and FAR in the one-question condition, whereas in the twoquestion condition, the HR was very stable, and the FAR showed an increase across initial lags before also becoming stable. (2) In the two-question condition, in relation to the one-question condition, there would be a decline in the incongruent-question FAR that would not be present in the new-item FAR. This prediction was confirmed by a significant interaction between number of questions asked

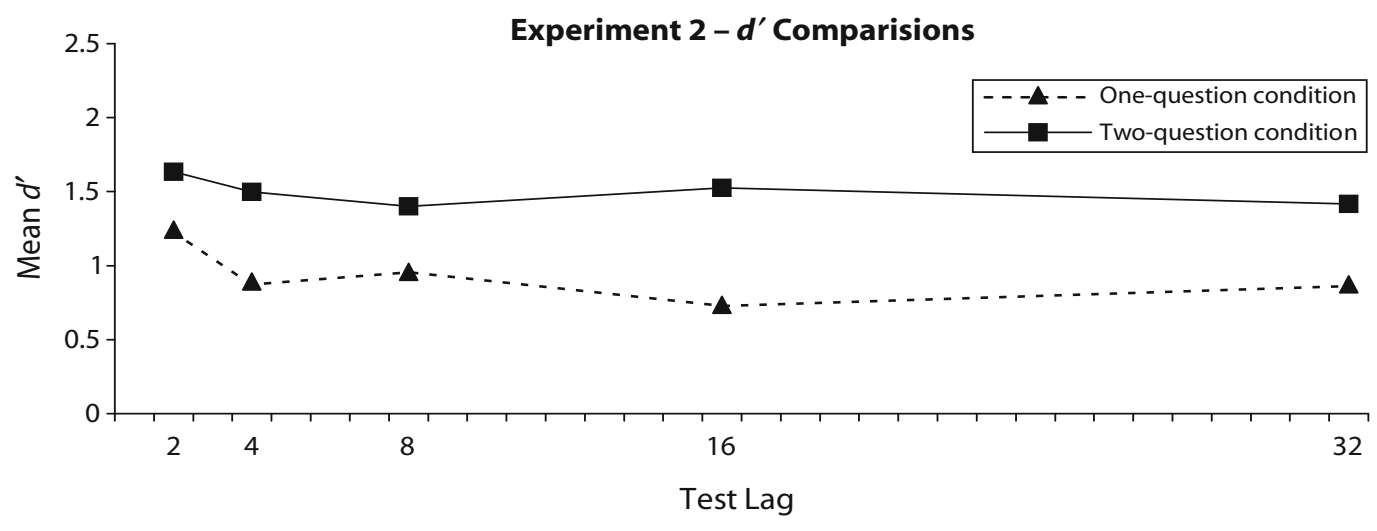

Figure 5. Mean $d^{\prime}$ estimates for the one-question and two-question conditions of Experiment 2. 
and test type (incongruent vs. new); although confidence ratings to new items did not differ across the one- and two-question conditions, participants who were asked only one question placed significantly more confidence in incongruent test items than did participants who were asked two questions. (3) There might be a significant difference in sensitivity estimates, namely $d^{\prime}$, favoring the two-question condition over the one-question condition. This prediction was also supported. Participants in the two-question condition appear to have more or more relevant information on which to base their responses than do participants in the one-question condition. Participants in the two-question condition accordingly make more accurate judgments with regard to plurality discrimination.

There are effects in our data we cannot explain at this time, such as the initial rise in mean confidence ratings to incongruent items at the very short lags for the twoquestion condition; Yonelinas and Levy (2002) also found an initial increase in their single-question source monitoring task. Short-term memory, implicit recall, and changes in the correlations between matching strengths could all contribute to these effects. Nevertheless, it seems safe to describe forgetting in these experiments as being buffered. That is, in neither of our conditions did $d^{\prime}$ consistently decline throughout the range of lags examined.

\section{EXPERIMENT 3}

Experiment 3 was designed to examine whether a buffered forgetting curve would also be found with verbal discrimination. In verbal discrimination, participants study pairs of items, with one item marked as the correct alternative. At test, they are required to identify the item in the pair that was the correct item. As discussed previously, verbal discrimination learning appears to rely on the frequency with which the correct alternative is read, rehearsed, and/or pronounced (Eckstrand et al., 1966), which can be likened to increasing the familiarity of the correct alternative in relation to the familiarity of the incorrect alternative. Thus, verbal discrimination may not necessarily rely on recollective processes. If we can demonstrate that a flat retention curve is present for verbal discrimination, we will have provided an example of another situation for which there is an apparently stable retention curve, or a buffered forgetting curve, despite our knowing that the underlying information is generally assumed to be forgotten.

\section{Method}

Participants. Twenty participants took part in this experiment. All had responded to an advertisement at the university campus and were paid a small sum of money for their time. Most were undergraduate students at the University of Queensland.

Design. For this experiment, we used a quasicontinuous verbal discrimination task and employed a within-subjects design. Study and test trials were intermixed within a single list, and five levels of lag were tested: $2,4,8,16$, and 32. Study trials were composed of pairs of words, with one member appearing in parentheses; for half the study trials, this was the left member, and for the other half, this was the right member. For test trials, participants were provided with previously presented study pairs and were instructed to "Please click on the word that previously appeared in brackets." For half of the test trials, the order of pair presentation was the same as the order in which the study pair had appeared, and for the other half, the order was reversed.

Materials and Procedure. The stimuli for this list were four- to eight-letter words of intermediate to high frequency (30-250 occurrences per million words) selected from the SMH Word Database (Dennis, 1995). There were 600 list trials, including 450 study trials and 150 test trials (30 tests at each level of lag). Each study pair remained on the screen for $2,500 \mathrm{msec}$ and was replaced by a $250-$ msec blank screen before the next trial, whereas test pairs remained on the screen until a response was made. Pairs were presented in lowercase, black, 24-point MS sans serif font in the center of the computer screen, and the two words were separated by about $10 \mathrm{~mm}$. The study pair member that appeared in parentheses (the left or right member) was randomized for each participant, and the order in which pairs appeared in test trials (same as at study or reversed) was also randomized for each participant. Participants were fully informed of the nature of the experiment, and, in general, sessions lasted about $30 \mathrm{~min}$.

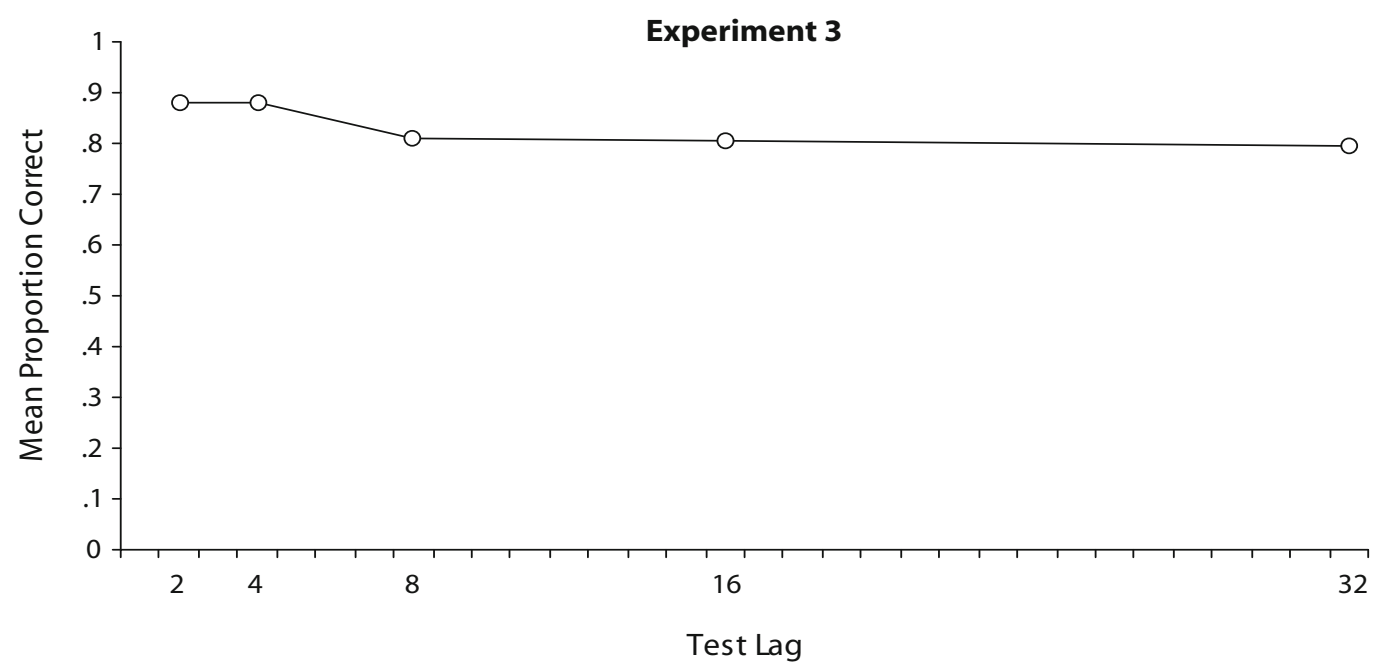

Figure 6. Average proportion correct as a function of test lag in the verbal discrimination task of Experiment 3. 


\section{Results}

The dependent variable was participants' average proportion correct at each level of test lag. These means are shown in Figure 6. To examine the verbal discrimination forgetting curve, we conducted a one-way repeated measures ANOVA with lag $(2,4,8,16,32)$ as the independent variable. A significant main effect for lag was found $\left[F(4,76)=6.006, M S_{\mathrm{e}}=.006, p<.001, \eta_{\mathrm{p}}^{2}=.240\right]$, indicating that, across the range of lags, there was a significant decline. Helmert contrasts suggested, however, that this decline was only present at the earliest lags, with the mean proportion correct at Lag 2 being significantly greater than the average of subsequent lags $[F(1,19)=$ 8.996, $\left.M S_{\mathrm{e}}=.007, p=.007, \eta_{\mathrm{p}}^{2}=.321\right]$, and similarly for Lag $4\left[F(1,19)=12.253, M S_{\mathrm{e}}=.009, p=.002, \eta_{\mathrm{p}}^{2}=\right.$ .392]. From Lag 6 onward, there appeared to be no decline in the proportion correct $\left(F_{\mathrm{S}}<1\right)$.

\section{Discussion}

In this verbal discrimination experiment, performance at Lags 2 and 4 was superior to performance at the later lags; however, from Lag 8 to Lag 32, there was essentially no decline. We thus have another example for which the retention function is surprisingly flat. If we are correct in our assumption that participants in the verbal discrimination task choose the more familiar member of the pair, in accordance with the frequency theory, then the explanation does not lie in an assumption about some source of information that does not decline. Instead, the flatness of the retention curve results from the forgetting of both targets and distractors. In this situation, a flat retention function would also occur if recollection were stable and if it only occurred to the correct alternative. This hypothesis, however, cannot explain performance in Eckstrand et al.'s (1966) both wrong condition, nor can it explain the effects of cumulative PI on verbal discrimination learning, which will be discussed shortly.

\section{GENERAL DISCUSSION}

Observations of flat $d^{\prime}$ and forced-choice retention functions for pairs - in contrast with those for single items - have been interpreted as being evidence for reduced forgetting of information that supports pair recognition (Hockley, 1991, 1992). Similarly, Yonelinas and Levy (2002) interpreted their finding that there was a parallel decline in yes responses to congruent and incongruent source monitoring questions as indicating that recollection is stable across short retention intervals. What we have tried to do in (1) our item and pair recognition study, in which we attempted to discount the use of item familiarity in pair recognition decisions; (2) our plurality study, in which we showed that false alarms to incongruent test items could be reduced; and (3) our demonstration that relatively flat retention functions can be obtained using verbal discrimination learning, is to show that there is an alternative to the assumption that there is no forgetting when forgetting functions appear flat. In each of these examples, there is some evidence from either the experiment or from the prior literature that is inconsistent with the Yonelinas and Levy explanation. The alternative we are proposing is that there is forgetting, but that there is relatively little change in the $d^{\prime}$ or forced-choice retention function, because there is forgetting of the distractor as well as of the target. That we have provided some evidence contrary to the Yonelinas and Levy explanation, together with an alternative explanation, does not mean that the Yonelinas and Levy explanation is necessarily incorrect for some or all of the areas investigated. It does, however, raise the standard of evidence required before such an explanation can be confidently accepted.

Other anomalous findings in the forgetting literature may also be attributable to the failure to consider the possibility that both targets and distractors can be forgotten. For example, Underwood, Broder, and Zimmerman (1973a) reported that cumulative PI had no effect on an associative matching task. Likewise, Underwood et al. (1973b) reported that cumulative PI had no effect on verbal discrimination learning. Postman and Keppel (1977) replicated this finding with respect to verbal discrimination learning. In the Postman and Keppel experiment, participants learned a first list, to a criterion of one perfect trial, on a Monday. They returned on a Wednesday and were tested on Monday's list before learning a new list. They returned on Friday to be tested on Wednesday's list and learned a new list. The next return was on the following Monday, and this continued across three weeks. Performance after $48 \mathrm{~h}$ was very good (nearly $90 \%$ ) and showed little variation over the three-week period. That is, there was little or no forgetting and no cumulative PI. This is in spite of the same design producing considerable cumulative PI with both cued and free recall.

This failure to find cumulative PI with these tasks had been reified in the assertion that recognition was not subject to proactive interference (Underwood, 1978). That is, associative matching was considered to be a form of pair recognition, and verbal discrimination learning and single-item recognition were both assumed to rely on frequency (Underwood \& Humphreys, 1979). However, if the frequency theory of verbal discrimination learning were correct, as was assumed by the authors of those studies, then both the correct alternative and the incorrect alternative within a pair would be subject to the same forgetting processes over the 48-h period. If forgetting occurs for both the correct and incorrect alternatives, the observed amount of forgetting in the verbal discrimination task underestimates the amount of forgetting of one's theoretical construct, whether this is frequency information or familiarity. Furthermore, the conclusion that recognition, frequency, or familiarity is not subject to PI may also be wrong.

\section{Signal Strength and Noise}

Up until now we have been considering recognitiontype paradigms, where there is a target and a distractor. However, if we generalize the idea of a distractor to the idea of noise, it is possible to apply these ideas to recall. For example, in a classic paper, Underwood (1957) looked at retention as a function of the number of prior lists learned in the laboratory. He reviewed the findings 
of a number of experiments for which learning had been a criterion of the participant's having gone once through the list without error, and retention was measured after $24 \mathrm{~h}$, using recall. Underwood (1957) concluded that, for a naive participant (someone who had learned no prior lists in the laboratory), forgetting could be as low as $15 \%$ over $24 \mathrm{~h}$, whereas, for an experienced participant (someone who had learned 20 or more lists previously), forgetting over $24 \mathrm{~h}$ could be as much as $75 \%$. It is this relatively low estimate of forgetting for naive participants, coupled with the extreme sensitivity to the learning of prior lists in the laboratory, that suggests that PI is far more important than retroactive interference (RI). This analysis, however, does not consider the interfering effects of the other pairs in the lists. It seems probable that, as a participant learns a paired-associates list, the other pairs in the list are a source of noise. The basic assumption here is that the difference in strength between the target and the noise (the contribution from all other list items) controls performance, but not the absolute strength of the target. This assumption about the other items in a list being a source of noise has been expressly addressed within the context of the global matching models (Eich, 1982; Humphreys, Bain, \& Pike, 1989; Ratcliff, Clark, \& Shiffrin, 1990). In such models, the test cue tends to activate its associate, as well as weakly activating the associates of all the cues in the list. These partially or weakly activated associates prevent the associate of the cue from being recalled.

Over a series of study trials, both the target and the other items within a list are strengthened. In order for performance to improve, target strength must increase at a faster rate than the strength of the noise from the other list items. That is, the relative strength of target and noise must diverge, even though the absolute strength of both increases. As would be the case in many of the studies considered by Underwood (1957), over $24 \mathrm{~h}$, the forgetting processes that weaken the association between a cue and its target would also weaken the associations between the other list cues and their targets. In other words, target strength will decline due to forgetting, but so will the strength of the noise coming from the other pairs in the list. Because he failed to consider a role for the other pairs within a list, Underwood (1957) may well have overestimated the contribution of PI and underestimated that of RI.

If our conclusion about the necessity of determining how both the signal and the noise components are forgotten is correct, then there is not just a problem with classical ideas about forgetting, such as in Underwood (1957). Most, if not all, contemporary thinking about forgetting - such as Anderson and Milson's (1989) rational analysis and Wixted's (2004) comparison of consolidation and interference - would also be inadequate. That is, researchers have been characterizing forgetting as a property of an item or association and measuring forgetting in paradigms that only allow conclusions about changes in discriminability.

\section{Conclusions}

Conditions where the strength of both targets and distractors declines with retention interval, or where the strength both of targets and of the noise from other list items or pairs declines, are ubiquitous in the forgetting literature. We propose that, under these conditions, forgetting should be referred to as being buffered. That is, forgetting appears to be slower than it actually is. In recognition paradigms, this apparent slowing of forgetting occurs because we measure memory performance in terms of targets in relation to distractors. In recall, forgetting occurs because, with human participants, we almost never train on a single item or single association. As long as we use lists of items, forgetting can be apparently slowed, because forgetting processes operate on both targets and other list items, the latter constituting noise.

\section{AUTHOR NOTE}

This work was supported in part through Grant DP0342656 from the Australian Research Council to the second author. We thank Andy Yonelinas for making his data available to us. Correspondence regarding this article should be addressed to M. S. Humphreys, Centre for Human Factors, University of Queensland, QLD 4072, Australia (e-mail: mh@) humanfactors.uq.edu.au).

\section{REFERENCES}

Anderson, J. R., \& Milson, R. (1989). Human memory: An adaptive perspective. Psychological Review, 96, 703-719.

BANKS, W. P. (2000). Recognition and source memory as multivariate decision processes. Psychological Science, 11, 267-273.

Clark, S. E. (1992). Word frequency effects in associative and item recognition. Memory \& Cognition, 20, 231-243.

Clark, S. E., \& Gronlund, S. D. (1996). Global matching models of recognition memory: How the models match the data. Psychonomic Bulletin \& Review, 3, 37-60.

DenNis, S. (1995). Sydney Morning Herald Word Database. Noetica: Open Forum, 1(4). Retrieved May 6, 2003, from psy.uq.edu.au/ CogPsych/Noetica/.

Dennis, S., \& Humphreys, M. S. (2001). A context noise model of episodic word recognition. Psychological Review, 108, 452-478.

DonalDSON, W. (1996). The role of decision processes in remembering and knowing. Memory \& Cognition, 24, 523-533.

ECKert, E., \& KANAK, J. N. (1974). Verbal discrimination learning: A review of the acquisition, transfer, and retention literature. Psychological Bulletin, 81, 582-607.

Eckstrand, B. R., Wallace, W. P., \& Underwood, B. J. (1966). A frequency theory of verbal-discrimination learning. Psychological Review, 73, 566-578.

EICH, J. M. (1982). A composite holographic associative recall model. Psychological Review, 89, 627-661.

Heathcote, A., Raymond, F., \& Dunn, J. (2006). Recollection and familiarity in recognition memory: Evidence from ROC curves. Journal of Memory \& Language, 55, 495-514.

HintzMAN, D. L. (1988). Judgments of frequency and recognition memory in a multiple-trace memory model. Psychological Review, 95, 528-551.

Hintzman, D. L., \& Curran, T. (1994). Retrieval dynamics of recognition and frequency judgments: Evidence for separate processes of familiarity and recall. Journal of Memory \& Language, 33, 1-18.

Hockley, W. E. (1982). Retrieval processes in continuous recognition. Journal of Experimental Psychology: Learning, Memory, \& Cognition, 8, 497-512.

HockLEY, W. E. (1991). Recognition memory for item and associative information: A comparison of forgetting rates. In W. E. Hockley \& S. Lewandowsky (Eds.), Relating theory and data: Essays on human memory in honor of Bennet B. Murdock (pp. 227-248). Hillsdale, NJ: Erlbaum.

HockLEY, W. E. (1992). Item versus associative information: Further comparisons of forgetting rates. Journal of Experimental Psychology: Learning, Memory, \& Cognition, 18, 1321-1330.

Humphreys, M. S., Bain, J. D., \& Pike, R. (1989). Different ways to 
cue a coherent memory system: A theory for episodic, semantic, and procedural tasks. Psychological Review, 96, 208-233.

Humphreys, M. S., Dennis, S., Maguire, A. M., Reynolds, K., Bolland, S. W., \& Hughes, J. D. (2003). What you get out of memory depends on the question you ask. Journal of Experimental Psychology: Learning, Memory, \& Cognition, 29, 797-812.

Humphreys, M. S., Pike, R., Bain, J. D., \& Tehan, G. (1989). Global matching: A comparison of the SAM, Minerva II, Matrix and TODAM models. Journal of Mathematical Psychology, 33, 36-67.

JACOBY, L. L. (1991). A process dissociation framework: Separating automatic from intentional uses of memory. Journal of Memory \& Language, 30, 513-541.

MandLeR, G. (1980). Recognizing: The judgment of previous occurrence. Psychological Review, 87, 252-271.

Murdock, B. B. (1997). Context and mediators in a theory of distributed associative memory (TODAM2). Psychological Review, 104, 839-862.

Murdock, B. B., \& Hockley, W. E. (1989). Short-term memory for associations. In G. H. Bower (Ed.), The psychology of learning and motivation (Vol. 24, pp.71-108). San Diego: Academic Press.

Postman, L., \& Keppel, G. (1977). Conditions of cumulative proactive inhibition. Journal of Experimental Psychology: General, 106, 376-403.

Ratcliff, R., Clark, S. E., \& Shiffrin, R. M. (1990). List-strength effect: I. Data and discussion. Journal of Experimental Psychology: Learning, Memory, \& Cognition, 16, 163-178.

Ratcliff, R., Van Zandt, T., \& McKoon, G. (1995). Process dissociation, single-process theories, and recognition memory. Journal of Experimental Psychology: General, 124, 352-374.

Rotello, C. M., \& Heit, E. (1999). Two-process models of recognition memory: Evidence for recall-to-reject? Journal of Memory \& Language, 40, 432-453.

Rotello, C. M., Macmillan, N. A., \& Van Tassel, G. (2000). Recall-to-reject in recognition: Evidence from ROC curves. Journal of Memory \& Language, 43, 67-88.

Rubin, D. C., Hinton, S., \& Wenzel, A. (1999). The precise time course of retention. Journal of Experimental Psychology: Learning, Memory, \& Cognition, 25, 1161-1176.

Slamecka, N. J. (1991). The analysis of recognition. In W. E. Hockley \& S. Lewandowsky (Eds.), Relating theory and data: Essays on human memory in honor of Bennet B. Murdock (pp. 297-306). Hillsdale, NJ: Erlbaum.

SNOdgrass, J. G., \& CoRwin, J. (1988). Pragmatics of measuring recognition memory: Applications to dementia and amnesia. Journal of Experimental Psychology: General, 117, 34-50.
Underwood, B. J. (1957). Interference and forgetting. Psychological Review, 64, 49-60.

UNDERWOOD, B. J. (1978). Recognition memory as a function of length of study list. Bulletin of the Psychonomic Society, 12, 89-91.

Underwood, B. J., Broder, P. K., \& Zimmerman, J. (1973a). Associative matching and cumulative proactive inhibition. Bulletin of the Psychonomic Society, 1, 48.

Underwood, B. J., Broder, P. K., \& Zimmerman, J. (1973b). Retention of verbal discrimination lists as a function of number of prior lists, word frequency, and type of list. Journal of Experimental Psychology, 100, 101-105.

Underwood, B. J., \& Humphreys, M. S. (1979). Context change and the role of meaning in word recognition. American Journal of Psychology, 92, 577-609.

WiXTED, J. T. (2004). On common ground: Jost's (1897) law of forgetting and Ribot's law of retrograde amnesia. Psychological Review, 111, 864-879.

YonELINAS, A. P. (1994). Receiver-operating characteristics in recognition memory: Evidence for a dual-process model. Journal of Experimental Psychology: Learning, Memory, \& Cognition, 20, 13411354.

Yonelinas, A. P. (1999). The contribution of recollection and familiarity to recognition and source-memory judgments: A formal dualprocess model and an analysis of receiver operating characteristics. Journal of Experimental Psychology: Learning, Memory, \& Cognition, 25, 1415-1434.

Yonelinas, A. P., \& Levy, B. J. (2002). Dissociating familiarity from recollection in human recognition memory: Different rates of forgetting over short retention intervals. Psychonomic Bulletin \& Review, 9, 575-582.

\section{NOTES}

1. Our use of the term buffered forgetting is based on an analogy with a buffered reaction in chemistry. That is, the addition of a salt to a solution can reduce the rate at which the $\mathrm{pH}$ of a solution changes.

2. In Yonelinas and Levy (2002), a lag of 1 referred to a test that immediately followed the study event. In our experiments, a lag of 1 refers to one event, either a study or test, intervening between the study and test events. In Figure 1, we have used our definition of lag to plot Yonelinas and Levy's results.

(Manuscript received February 16, 2006; revision accepted for publication September 25, 2006.) 